\title{
Engineering Robust Polar Chiral Clathrate Crystals $\uparrow$
}

\author{
Christopher S. Frampton, ${ }^{* a}$ Kamal A. Ketuly, $^{b}$ A. Hamid A. Hadi, ${ }^{b}$ James H. Gall $^{\mathrm{c}}$ and \\ David D. MacNicol.*c
}

The $R$-(+)-enantiomeric form of Dianin's compound and the $S$-(+)-enantiomeric form of its direct thiachroman analogue both obtained chromatographically employing a cellulose tris(3,5dimethylphenylcarbamate) column, are shown to undergo supramolecular assembly to form a polar clathrate lattice which is stable even in the absence of a consolidating guest component.

Crystal engineering is a major theme of current chemical research ${ }^{1}$. In particular the design of clathrates, in a classical sense cage-type multimolecular crystalline inclusion compounds, has not only inherent scientific interest but is also important for the supramolecular assembly of new systems with applications in, for example, drug delivery, isomer separation, optical resolutions, storage of toxic and reactive materials and second harmonic generation. It has now been firmly established that judicious modification of an appropriate host molecule, based on a knowledge of the crystal structure of the parent host lattice, can lead to new inclusion compounds $^{2}$ of both the channel ${ }^{3}$ and true closed-cage clathrate ${ }^{4,5}$ types.

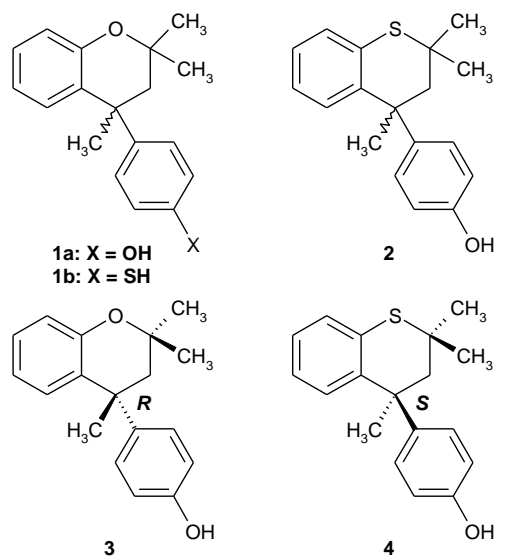

Scheme 1 Dianin's compound and structural variants

The present work is concerned with crystal engineering related to Dianin's compound 1a, (Scheme 1), the remarkable inclusion properties of which were first reported in 1914 by A.P.Dianin ${ }^{6}$, a student and biographer of the chemist and composer Alexander Borodin. The parent host 1a, which does not possess an enforced intramolecular cavity, is particularly attractive from the viewpoint of carefully chosen structural modification. It offers multiple points of substitution, variation of the two functional groups and of crucial importance to the present work is chiral and can be resolved into its two enantiomers ${ }^{7}$. At the end of the 1960's it was established that both compound $\mathbf{1} \mathbf{a}^{8}$ and its thia analogue 4-p-hydroxyphenyl-2,2,4-trimethylthiachroman, (ThiaDianin's compound), $\mathbf{2}^{9,10}$, (Scheme 1), form isomorphous and isostructural clathrates in the centrosymmetric space group $R \overline{3}$, with the two host lattices being stable even in the absence of a guest. Further packing modes involving 1a, demonstrating the breakdown of the isomorphous and isostructural behaviour of Dianin's compound along with computational stability studies on the host lattice have also been studied ${ }^{11}$. In a recent paper Jacobs et al. presented a quasiracemic organic host prepared from the cocrystallisation of the resolved enantiomers of Dianin's compound $\mathbf{1 a}$ and its mercapto analogue $\mathbf{1} \mathbf{b}^{13}$. Cocrystallisation of $(R)-\mathbf{1 a}$ and $(S)-\mathbf{1 b}$ from $\mathrm{CCl}_{4}$ produced a $\mathrm{CCl}_{4}$ clathrate structure in the polar and chiral space group $R 3$ featuring an $\left[\mathrm{SH}^{\cdots} \mathrm{OH}\right]_{3}$ hexamer replacing the $[\mathrm{OH}]_{6}$ and $[\mathrm{SH}]_{6}$ hexamers of racemic $\mathbf{1 a}$ and $\mathbf{1 b}$ respectively. The reduction in symmetry from $R \overline{3}$ to $R 3$ allowed for the polar ordering of the $\mathrm{CCl}_{4}$ guest molecules, (two per cage), such that a preferential alignment of the $\mathrm{C}-\mathrm{Cl}$ bonds along the polar axis toward the host phenolic moiety was achieved in the ratio of 85 : 15. Desolvation of this material however resulted in spontaneously resolved $(R)-\mathbf{1 a}$ and $(S)$-1b demonstrating that the incorporation of a stabilising guest is crucial for the host lattice stability.

Herein we now report the first optical resolution of $\mathbf{2}$, employing the homochiral column material cellulose tris(3,5-dimethylphenylcarbamate), as well as the first chromatographic resolution of parent 1a to yield 
enantiomerically pure samples of both $R$-(+)-Dianin's compound, $3 \ddagger$ and $S$-(+)-ThiaDianin's compound, $4 \ddagger$, as well as their optically pure antipodes ${ }^{12}$. The resolved enantiomers of 1 have m.p. $142-142.5^{\circ} \mathrm{C}$, (Lit. $^{7} 140^{\circ} \mathrm{C}$ ), and those of 2 m.p. $118-120^{\circ} \mathrm{C}$.

Cocrystallisation of equimolar quantities of $\mathbf{3}$ and $\mathbf{4}$ from $\mathrm{CCl}_{4}$ is shown to form a novel polar clathrate, $\mathbf{5}$ t, which is of potential interest for Second Harmonic Generation whilst cocrystallisation from $n$-decane yields a quasiracemic polar host structure, $\mathbf{6}+$, that has an unoccupied cavity demonstrating that guest incorporation is not required in this particular case for host lattice stability. As described below the absolute configurations of enantiomerically pure $\mathbf{3}$ and $\mathbf{4}$ have been determined in their orthorhombic molecular crystals, in which the molecular conformations observed are quite distinct from those found in the new polar crystal, further details contained within the ESI. The preparation

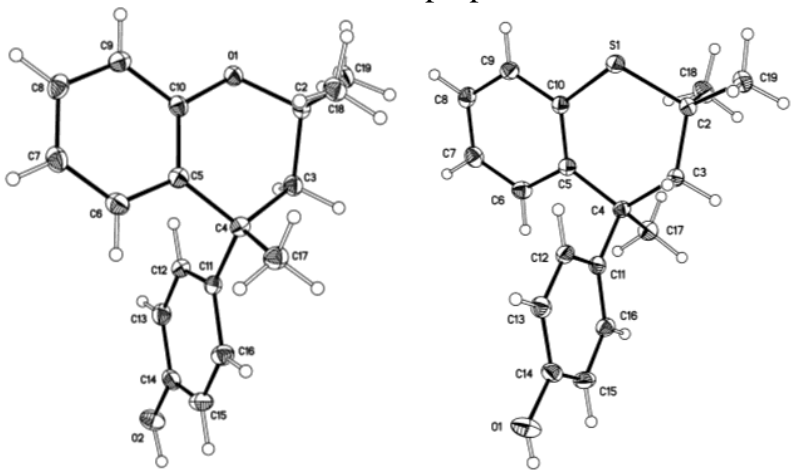

Fig. 1 ORTEP views of the single enantiomers of $\mathbf{3}$ and 4.

and optical resolution of $1 \mathbf{a}$ and $\mathbf{2}$ by chromatographic methods was performed as outlined in Ref. 13 and in each case the enantiomer with the $R$ configuration was eluted first from the column.

The crystal structures of both $\mathbf{3}$ and $\mathbf{4}$, (Fig. 1), were determined to prove the absolute configuration and conformation of the resolved enantiomers prior to performing the cocrystallisation to prepare polar clathrates. The results for the former analysis on dextrorotatory $\mathbf{3}$ which has the $R$ configuration (vide infra) are in complete accordance with the elegant assignment by Collet and Jacques ${ }^{14}$ of the absolute configuration for $S$-(-)Dianin's compound, the opposite enantiomer; and also consistent with the crystal structure of the $S$-enantiomer prepared from $(S, S)-4-\left(2,2,4-\right.$ trimethylchroman-4-yl)phenyl camphanate ${ }^{15}$. The crystal stuctures of $\mathbf{3}$ and $\mathbf{4}$, (Figures 1a and 1b), are both isostructural and isomorphous with each other and also with the enantiomerically pure forms of 4-(2,4-dihydroxyphenyl)-2,2,4-

trimethylchroman ${ }^{16}, R$-4-(4-aminophenyl)-2,2,4-trimethyl- chroman ${ }^{17}$ and $S$-4-(4-aminophenyl)-2,2,4-trimethylthiachroman structures ${ }^{17}$ in the orthorhombic space group $P 22_{1} 2_{1} 2_{1}$, with $Z=4$. For both compounds the heterocyclic chroman ring adopts an envelope conformation or $E$-form with atom $\mathrm{C} 2$ displaced from from the mean plane defined by atoms O1/S1, C10, C5, C4, C 3 by -0.647 and $-0.805(2) \AA$ respectively which is directly comparable with the displacements of $-0.649,-0.647,-0.641$ and $-0.809 \AA$ found for atom $\mathrm{C} 2$ in the crystal structures of $S$-Dianin's compound, 4-(2,4-dihydroxyphenyl)-2,2,4-trimethyl-chroman, $R$-4-(4-aminophenyl)2,2,4-trimethylchroman and $S$-4-(4-amino-phenyl)-2,2,4-trimethylthiachroman respectively. 


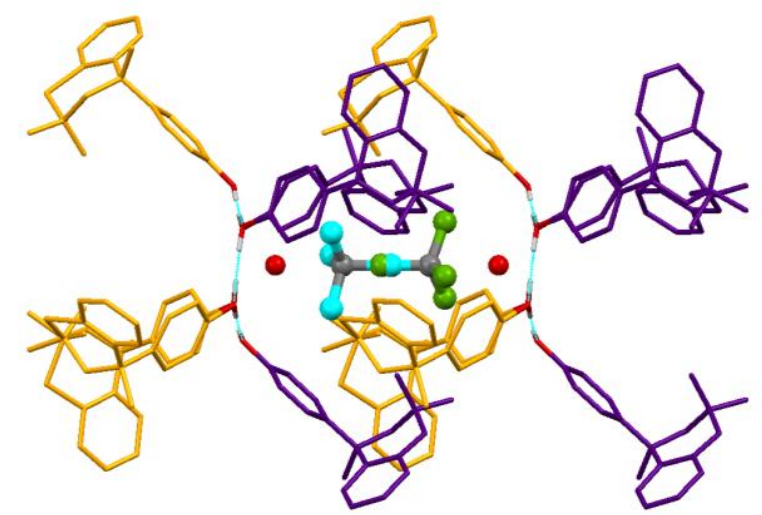

Fig. 2 Crystal structure of $\mathbf{5}$ viewed down the $b$-axis. Individual molecules of $\mathbf{3}$ and $\mathbf{4}$ are shown in purple and yellow respectively. Hydrogen bonds are shown as blue dashed lines.

Cocrystallisation of equimolar amounts of $\mathbf{3}$ and $\mathbf{4}$ from $\mathrm{CCl}_{4}$ gave the novel polar $\mathrm{CCl}_{4}$ clathrate, (one $\mathrm{CCl}_{4}$ per cage), 5, with the trigonal lattice parameters of $a=27.3283(4), c=10.8327(2) \AA$. In addition to the single disordered $\mathrm{CCl}_{4}$, the structure also contains a disordered water molecule on the three-fold axis at each end of the cavitiy, Fig. 2. The occupancy of the oxygen atom on the special position was fixed at 0.083 yielding an overall hemihydrate stoichiometry, the hydrogen atoms of the water molecule could not be located in the difference map owing to the disorder of this moiety over three potential hydrogen bond positions. The quasiracemic structure is closely related to the parent centrosymmetric $R \overline{3}$ structure with the exception that it exists in the lower symmetry polar space group $R 3$ with the two independent enantiomeric components $\mathbf{3}$ and $\mathbf{4}$ directed to opposing ends of the crystal along the polar trigonal axis. The absolute configuration was determined both from an a priori knowledge of the configuration of the starting components and from the the anomalous dispersion experiment which yielded a Flack parameter and its uncertainty for this structure of $0.032(9)^{18-20}$. The hydroxyl oxygen atoms in structure $\mathbf{5}$ are

referred to as $\mathrm{O} 2 \mathrm{~A}$ and $\mathrm{O} 2 \mathrm{~B}$ for the chroman and thiachoman components respectively. Alternating molecules of 3 and 4 self-assemble to form the expected $R_{6}{ }^{6}(12),[\mathrm{OH}]_{6}$ hydrogen bonded hexamer at each end of the classical 'hourglass' cavity with $\mathrm{O}_{2} \mathrm{~A}_{\text {donor }} \cdots \mathrm{O}^{2} \mathrm{~B}_{\text {acceptor }}$ and $\mathrm{O}_{2} \mathrm{~B}_{\text {donor }} \cdots \mathrm{O}^{2} \mathrm{~A}_{\text {acceptor }}=2.821(2)$ and 2.901(2) $\AA$ respectively. The single $\mathrm{CCl}_{4}$ guest moiety is disordered over two sites on the three-fold axis within the hourglass cavity. Owing to the the polar nature of the structure the disorder of the $\mathrm{CCl}_{4}$ guest is not a statistical $50: 50$ as would be the case in the centrosymmetric $R \overline{3}$ example and refinement of the occupancy of the two components yields a $70: 30$ ratio favoured in the projection of the axial $\mathrm{C}-\mathrm{Cl}$ bond directed towards the three $p$ hydroxyphenyl moieties of the three molecules of the thiachroman, $\mathbf{4}$, involved in forming the clathrate cage. The $70: 30$ components are shown in dark green and light blue respectively in Figure 2.

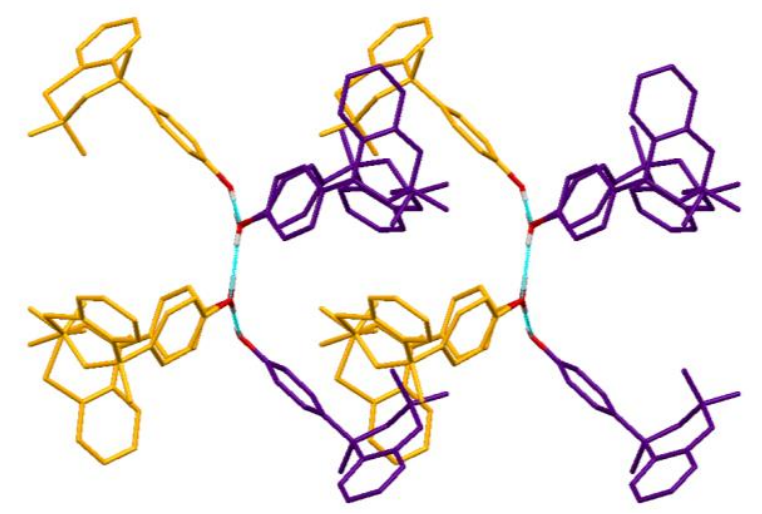

Fig. 3 Crystal structure of 6 viewed down the b-axis. Individual molecules of 3 and 4 are shown in purple and yellow respectively. Hydrogen bonds are shown as blue dashed lines.

The water molecule is located within a realistic hydrogen bonding distance from each $[\mathrm{OH}]_{6}$ hydrogen bonded hexamer and is disordered about the three fold axis yeilding a hydrogen bond distance of $\mathrm{O} 1_{\text {water donor }} \ldots$

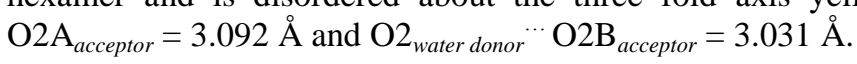


Cocrystallisation of equimolar amounts of $\mathbf{3}$ and $\mathbf{4}$ from $n$-decane yields the novel polar host structure $\mathbf{6}$, Fig. 3. This assembly is unique in the respect that it is the first quasiracemic polar host lattice structurally elucidated in the absence of a guest molecule. The structure demonstrates a completely empty hourglass cavity with a void space calculated to be $237.5 \AA^{3}$ using the solvent accessable surface method in the program Mercury ${ }^{21}$ with a probe radius of $1 \AA$. This is in good agreement with the value of $240 \AA^{3}$ reported previously for the centrosymmetric $R \overline{3}$ Dianin's and ThiaDianin's host compounds. As mentioned above the conformations of $\mathbf{3}$ and 4 exhibit a marked change on passing from their molecular crystals to the new quasiracemic rhombohedral lattice; for the 'empty' cage form both molecules have a distorted half-chair conformation for the heterocyclic rings with atoms $\mathrm{C} 2$ and $\mathrm{C} 3$ displaced from the mean plane of the remaing four ring atoms, with repective displacements of $+0.299(3)$ and $-0.376(3) \AA$ for 3 and $+0.476(3)$ and $-0.280(3) \AA$ for $\mathbf{4}$. Finally, an attractive possibility, currently under investigation, is the construction of what one might term pseudoquasi racemates where a single enantiomer of Dianin's compound, 1a, can potentially self assemble with a partner which is not inherently chiral but which exists as chiral conformations such as suitable molecules related to the parent host which correspond to (formal) opening of its heterocyclic ring.

\section{Notes and references}

${ }^{a}$ SAFC Pharmorphix ${ }^{\circledR}$, A Sigma Aldrich Company, 250 Cambridge Science Park, Milton Road, Cambridge, CB4 OWE, U.K. Fax: 441223 424930; Tel: 441223 425105; E-mail: chris.frampton@sial.com

${ }^{b}$ Chemistry Department, Faculty of Science, University of Malaya, 50603 Kuala Lumpur, Malaysia. E-mail: ahamid@um.edu.my

${ }^{c}$ School of Chemistry, Joseph Black Building, University of Glasgow, Glasgow G12 8QQ, UK. E-mail:

David.MacNicol@glasgow.ac.uk

$\dagger$ Electronic Supplementary Information (ESI) available: Absolute stereochemistry determination for compounds 3 and 4. CCDC 933470-933473 For ESI and crystallographic data in cif or other electronic format See DOI: 10.1039/b000000x/

Financial support from the Malaysia HIR MOHE, Grant No. : F000009-21001, is gratefully acknowledged. We wish to thank also Ainnul Hamida Syahadah (Malaysia) and Mrs. Kim Wilson (Glasgow) for valuable technical assistance.

† Crystal data for 3: $\mathrm{C}_{18} \mathrm{H}_{20} \mathrm{O}_{2}, M=268.34, a=10.0279(1) \AA, b=10.4702(1) \AA, c=13.2012(1) \AA, \alpha=90.00^{\circ}, \beta=90.00^{\circ}, \gamma$ $=90.00^{\circ}, V=1386.05(2) \AA^{3}, T=100(1) \mathrm{K}$, space group $P 2_{1} 2_{1} 2_{1}, Z=4, \mu(\mathrm{Cu} \mathrm{K \alpha})=0.646 \mathrm{~mm}^{-1}, 24324$ reflections measured, 2825 independent reflections $\left(R_{\text {int }}=0.0245\right)$. The final $R_{I}$ values were $0.0254(I>2 \sigma(I))$. The final $w R\left(F^{2}\right)$ values were $0.0684(I>2 \sigma(I))$. The final $R_{l}$ values were 0.0255 (all data). The final $w R\left(F^{2}\right)$ values were 0.0684 (all data). The goodness of fit on $F^{2}$ was 1.007. Flack parameter $=-0.03(15){ }^{18-20}$. Crystal data for 4: $\mathrm{C}_{18} \mathrm{H}_{20} \mathrm{OS}, M=284.40, a=10.5486(1)$ $\AA, b=10.5395(1) \AA, c=13.1045(2) \AA, \alpha=90.00^{\circ}, \beta=90.00^{\circ}, \gamma=90.00^{\circ}, V=1456.92(3) \AA^{3}, T=100(1) \mathrm{K}$, space group $P 2{ }_{1} 2_{1} 2_{1}, Z=4, \mu(\mathrm{Cu} \mathrm{K} \alpha)=1.896 \mathrm{~mm}^{-1}, 7286$ reflections measured, 2957 independent reflections $\left(R_{\text {int }}=0.0171\right)$. The final $R_{l}$ values were $0.0259(I>2 \sigma(I))$. The final $w R\left(F^{2}\right)$ values were $0.0700(I>2 \sigma(I))$. The final $R_{I}$ values were $0.0269($ all data). The final $w R\left(F^{2}\right)$ values were 0.0704 (all data). The goodness of fit on $F^{2}$ was 1.006. Flack parameter $=0.015(13)^{18-20}$. Crystal data for 5: $3\left(\mathrm{C}_{18} \mathrm{H}_{20} \mathrm{OS}\right) \cdot 3\left(\mathrm{C}_{18} \mathrm{H}_{20} \mathrm{O}_{2}\right) \cdot\left(\mathrm{CCl}_{4}\right) \cdot 0.5\left(\mathrm{H}_{2} \mathrm{O}\right), M=1821.04, a=27.3283(4) \AA, b=27.3283(4) \AA, c=$ $10.8327(3) \AA, \alpha=90.00^{\circ}, \beta=90.00^{\circ}, \gamma=120.00^{\circ}, V=7006.4(2) \AA^{3}, T=100(1) \mathrm{K}$, space group $R 3, Z=3, \mu(\mathrm{Cu} \mathrm{K \alpha})=2.254$ $\mathrm{mm}^{-1}, 13784$ reflections measured, 6061 independent reflections $\left(R_{\text {int }}=0.0201\right)$. The final $R_{l}$ values were $0.0323(I>2 \sigma(I))$. The final $w R\left(F^{2}\right)$ values were $0.0980(I>2 \sigma(I))$. The final $R_{l}$ values were 0.0332 (all data). The final $w R\left(F^{2}\right)$ values were 0.1037 (all data). The goodness of fit on $F^{2}$ was 1.001. Flack parameter $=0.032(9){ }^{18-20}$. Crystal data for 6: $\mathrm{C}_{18} \mathrm{H}_{20} \mathrm{OS} \cdot \mathrm{C}_{18} \mathrm{H}_{20} \mathrm{O}_{2}, M=552.74, a=27.2258(4) \AA, b=27.2258(4) \AA, c=10.8365(2) \AA, \alpha=90.00^{\circ}, \beta=90.00^{\circ}, \gamma=$ $120.00^{\circ}, V=6956.3(2) \AA^{3}, T=90(1) \mathrm{K}$, space group $R 3, Z=9, \mu(\mathrm{Cu} \mathrm{K \alpha})=1.183 \mathrm{~mm}^{-1}$, 17968 reflections measured, 6250 independent reflections $\left(R_{\text {int }}=0.0296\right)$. The final $R_{l}$ values were $0.0352(I>2 \sigma(I))$. The final $w R\left(F^{2}\right)$ values were $0.0952(I>$ $2 \sigma(I))$. The final $R_{l}$ values were 0.0374 (all data). The final $w R\left(F^{2}\right)$ values were 0.0975 (all data). The goodness of fit on $F^{2}$ was 1.002. Flack parameter $=0.002(12)^{18-20}$. All crystal structures were solved and refined using the SHELX suite of programs $^{22}$.

1 For useful general references see, for example,

G.R.Desiraju, Crystal engineering: the design of organic solids, Elsevier, Amsterdam, 1989, Crystal engineering:

Structure and function. Perspectives in Supramolecular Chemistry (founded by J.-M.Lehn), Wiley, Chichester, 2003 ; J.

D. Dunitz, Thoughts on Crystals as Supermolecules in Perspectives in Supramolecular Chemistry, The Crystal as a

Supramolecular Entity, Volume 2, ed. G. R. Desiraju, John Wiley \& Sons Ltd., Chichester UK, 2007,10.1002/ 9780470511459.ch1.

2 Comprehensive Supramolecular Chemistry, Vol. 6, edited by D. D. MacNicol, F. Toda and R. Bishop , 1996, Oxford , Elsevier Science..

3 See, for example, R. Bishop, Helical Host Lattices Formed by Alicyclic Diols.Ref. 2, Ch. 4, pp.85-115.

4 See, for example, D. D. MacNicol, Structure and design of inclusion compounds: the clathrates of hydroquinone, phenol, Dianin's compound and related systems. Inclusion Compounds, edited by J. L. Atwood, J. E. D. Davies and D. D. MacNicol, Academic Press, 1984, Vol. 2 , Ch.1, pp.12-32.

5 See, for example, F. Finocchiro and S. Failla, Other Potentially Important Hosts. Ref. 2, Ch. 18, pp. 618-632

6 A. P. Dianin, J. Russe. Phys. Chem. Soc., 1914, 46, 1310.

7 M. J. Brienne and J. Jacques, Tetrahedron Lett, 1975, 16, 2349. 
8 J. L. Flippen, J. Karle and I. L. Karle, J. Am. Chem. Soc., 1970, 92, 3749.

9 D. D. MacNicol, H. H. Mills and F. B. Wilson, Chem. Commun., 1969, 1332.

10 D. D. MacNicol, Chem, Commun., 1969, 836.

11 G. O. Lloyd, M. W. Bredenkamp \& L. J. Barbour, Chem. Commun., 2005, 4053; T. Jacobs, G. O. Lloyd, M. W. Bredenkamp \& L. J. Barbour, Cryst. Growth Des., 2009, 9, 1284; J. J. Lee, R. O. Fuller, A. N. Sobolev, H. F. Clausen, J. Overgaard, G. A. Koutsantonis, B. B. Iversen \& M. A. Spackman, Chem. Commun., 2011, 47, 2029; T. Jacobs, G. O. Lloyd, M. W. Bredenkamp \& L. J. Barbour, CrystEngComm, 2009, 1545; A. J. Cruz-Babeza, G. M. Day \& W. Jones, Chem. Eur. J., 2009, 15, 13033.

12 T. Jacobs, M. W. Bredenkamp, P. H. Neethling, E. G. Rohwer and L. J. Barbour, Chem. Commun., $2010,46,8341$.

13 Racemic compounds $\mathbf{1 a}^{23}$ and $\mathbf{2}^{9}$ prepared as indicated, were optically resolved using a Waters $600($ model code $60 \mathrm{~F})$ instrument with Waters 848 tunable absorbance detector. The chiral column employed was a $1.5 \mu \mathrm{m}, 250 \mathrm{x} 21.20 \mathrm{~mm}$ LuxTM-1 Cellulose tris(3,5-dimethylphenylcarbamate) column supplied by Phenomenex (USA). $n$-Hexane/isopropanol mixtures were used as eluents and the compositions were $96: 4$ and $97: 3 \mathrm{v} / \mathrm{v} \%$, respectively for 1a and 2. In each case the enantiomer with the $R$ configuration was eluted first.

14 A. Collet and J. Jacques, Isr. J. Chem., 1976/77, 15, 82.

15 G. O. Lloyd and M. W.Bredenkamp, 2005, Acta Crystallogr., E61, o1512.

16 T. W. Beresford, C. S. Frampton, J. H. Gall and D. D. MacNicol, 1999, Zh.Strukt. Khim., 40, 872.

17 C. S. Frampton, D. D. MacNicol and D. R. Wilson, Acta Crystallogr. 2011, C67, o188.

18 H. D. Flack, Acta Crystallogr., 1983, A39, 876; H. D. Flack and G. Bernardinelli, J. Appl. Crystallogr., $2000,33,1143$.

19 Hooft, R. W. W., Straver, L. H. \& Spek, A. L. (2008). J. Appl. Crystallogr., 41, 96.

20 A. L. Spek, 2009 Acta Crystallogr., D65, 148.

21 C. F. Macrae, I. J. Bruno, J. A. Chisholm, P. R. Edgington, P. McCabe, E. Pidcock, L. Rodriguez-Monge, R. Taylor, J. van de Streek and P. A.Wood, 2008. J. Appl. Crystallogr., 41, 466.

22 G. M. Sheldrick, 2008, Acta Crystallogr., A64, 112.

23 W. Baker, A. J. Floyd, J. F. W. McOmie, G. Pope, A. S. Weaving and J. H. Wild, J. Chem. Soc., 1956, 2010. 